\title{
Trophic ecology of the invasive argentine ant: spatio-temporal variation in resource assimilation and isotopic enrichment
}

\author{
Sean B. Menke $\cdot$ Andy V. Suarez $\cdot$ \\ Chadwick V. Tillberg $\cdot$ Cheng T. Chou \\ David A. Holway
}

Received: 26 February 2010/Accepted: 8 June 2010/Published online: 25 June 2010

(C) The Author(s) 2010. This article is published with open access at Springerlink.com

\begin{abstract}
Studies of food webs often employ stable isotopic approaches to infer trophic position and interaction strength without consideration of spatio-temporal variation in resource assimilation by constituent species. Using results from laboratory diet manipulations and monthly sampling of field populations, we illustrate how nitrogen isotopes may be used to quantify spatio-temporal variation in resource assimilation in ants. First, we determined nitrogen enrichment using a controlled laboratory experiment with the invasive Argentine ant (Linepithema humile). After 12 weeks, worker $\delta^{15} \mathrm{~N}$ values from colonies
\end{abstract}

Communicated by Phil Lester.

S. B. Menke · C. T. Chou · D. A. Holway

Division of Biological Sciences, University of California at San

Diego, La Jolla, 9500 Gilman Dr., La Jolla, CA 92093, USA

C. T. Chou

e-mail: ctchou@ucsd.edu

D. A. Holway

e-mail: dholway@ucsd.edu

A. V. Suarez

Department of Entomology and Department of Animal Biology,

University of Illinois, 320 Morrill Hall, 505 S. Goodwin Ave,

Urbana, IL 61801, USA

e-mail: avsuarez@life.uiuc.edu

\section{S. B. Menke ( $\square)$}

Department of Entomology and Department of Biology,

North Carolina State University, 3324 Gardner Hall,

Box 7613, Raleigh, NC 27695, USA

e-mail: sean_menke@ncsu.edu

C. V. Tillberg

Department of Biology, Linfield College,

McMinnville, OR 97128, USA

e-mail: ctillbe@linfield.edu fed an animal-based diet had $\delta^{15} \mathrm{~N}$ values that were $5.51 \%$ greater compared to colonies fed a plant-based diet. The shift in $\delta^{15} \mathrm{~N}$ values in response to the experimental diet occurred within 10 weeks. We next reared Argentine ant colonies with or without access to honeydew-producing aphids and found that after 8 weeks workers from colonies without access to aphids had $\delta^{15} \mathrm{~N}$ values that were $6.31 \%$ larger compared to colonies with access to honeydew. Second, we sampled field populations over a 1-year period to quantify spatio-temporal variability in isotopic ratios of L. humile and those of a common native ant (Solenopsis xyloni). Samples from free-living colonies revealed that fluctuations in $\delta^{15} \mathrm{~N}$ were $1.6-2.4 \%$ for L. humile and 1.8 $2.9 \%$ for S. xyloni. Variation was also detected among L. humile castes: time averaged means of $\delta^{15} \mathrm{~N}$ varied from 1.2 to $2.5 \%$ depending on the site, with $\delta^{15} \mathrm{~N}$ values for queens $\geq$ workers $>$ brood. The estimated trophic positions of L. humile and S. xyloni were similar within a site; however, trophic position for each species differed significantly at larger spatial scales. While stable isotopes are clearly useful for examining the trophic ecology of arthropod communities, our results suggest that caution is warranted when making ecological interpretations when stable isotope collections come from single time periods or life stages.

Keywords Argentine ant - Biological invasion . Stable isotope - Solenopsis xyloni $\cdot$ Trophic ecology

\section{Introduction}

The quantitative study of food webs has revolutionized our understanding of how biotic interactions, nutrient cycling, and energy flow structure assemblages of species. A recent 
focus of food web ecology concerns spatio-temporal variability in trophic position and the relative importance of omnivory (Mooney and Tillberg 2005; Polis et al. 2004; Schmidt et al. 2007; Tillberg and Breed 2004). Research in this area has also yielded insights into the ecological effects of biological invasions, which can disrupt ecosystems by acting as novel consumers (Diamond and Case 1986; Fritts and Rodda 1998; Pimm et al. 1991) and competitors (Elton 1958; Holway et al. 2002; Petren and Case 1998; Sanders et al. 2003). In invaded systems, simple predator-prey relationships may be atypical because introduced consumers often scavenge and engage in intra-guild predation (Fritts and Rodda 1998; Snyder and Evans 2006; Wilson et al. 2009). Introduced species can also be key competitors, and, in combination with their effects as predators, can reduce the diversity and abundance of native species where they successfully invade (Elton 1958; Mack et al. 2000; Vitousek et al. 1996).

Quantitative studies on invasions have benefited enormously from stable isotope techniques, which can yield powerful insights into the study of food webs (Dawson et al. 2002; Ehleringer et al. 1986; Gannes et al. 1997), including those invaded by introduced consumers (Gorokhova et al. 2005; Rudnick and Resh 2005; Tillberg et al. 2007; Vander Zanden et al. 1999). Because an organism's isotopic composition provides a record of resources assimilated, isotopes allow the tracking of nutrients through food webs and can also be used to estimate trophic position (Langellotto et al. 2006; Layman et al. 2007; Post 2002). For animals with feeding behavior that is difficult to observe or to quantify, isotopic analyses also permit insights into the relative consumption of different food items. With respect to nitrogen isotopes, for example, consumers are enriched (i.e., they have a higher ${ }^{15} \mathrm{~N} /{ }^{14} \mathrm{~N}$ ) relative to their prey. Research to date on insects generally reports a $\delta^{15} \mathrm{~N}$ enrichment of 2-3\% per trophic level (Cabana and Rasmussen 1994; Deniro and Epstein 1981; Minagawa and Wada 1984; Mooney and Tillberg 2005; Owens 1987), although this number varies with food quality, the type of organism, and its age (McCutchan et al. 2003; Oelbermann and Scheu 2002; Sagers and Goggin 2007; Vanderklift and Ponsard 2003). Recent work by Spence and Rosenheim (2005) suggests that, for certain food webs, it may be necessary to determine the level of isotopic enrichment for each trophic link.

Nitrogen isotopic analyses have revealed surprising information concerning trophic relationships within ant assemblages (Davidson et al. 2003; Feldhaar et al. 2009; Tillberg et al. 2007) and the specific roles that ants play in mutualisms with plants (Tillberg 2004; Treseder et al. 1995). Isotopic analyses may also clarify the effects of ant invasions. Although invasive ants can disrupt ecosystems
(Holway et al. 2002; O’Dowd et al. 2003), it often remains unclear what these insects consume, at least in part because they feed on liquids (Lach 2003; Markin 1970; Tennant and Porter 1991). The ecological role of invasive ants is further obscured by seasonally shifting macronutrient preferences and because these insects simultaneously act as predators, scavengers and herbivores (Helms and Vinson 2002; Holway et al. 2002; Tennant and Porter 1991). In certain environments, for example, invasive ants may indirectly function as herbivores during seasons when hemipteran honeydew is plentiful and then turn to scavenging and predation as plant-based resources become less available. Food web studies usually ignore temporal variation in diet even though it has important implications, particularly for scavenging predators (Mooney and Tillberg 2005; Wilson et al. 2009).

In this study, we use experimental manipulations to inform the results of observational surveys in order to better understand how temporal variation in resource assimilation affects isotopic signatures. We focus on the invasive Argentine ant (Linepithema humile), and a common native fire ant, Solenopsis xyloni. The Argentine ant is a widespread, abundant, and ecologically damaging invasive species that forms spatially expansive supercolonies, and has a global distribution (Holway et al. 2002; Suarez et al. 2001). We address the following questions. First, if invasive ants shift the extent to which they assimilate plantbased resources in space and time, are such shifts evident from patterns of $\delta^{15} \mathrm{~N}$ enrichment? If so, how rapidly do these shifts occur? To answer these questions, we conducted diet-manipulation studies in the laboratory and greenhouse to quantify how assimilation of animal-based versus plant-based diets affects the rate of $\delta^{15} \mathrm{~N}$ enrichment (Ostrom et al. 1997). Second, if the $\delta^{15} \mathrm{~N}$ values of ant colonies change in response to the assimilation of plantbased resources, do such shifts occur on a seasonal basis as plant-based resources vary in their availability? To address this question, we sampled Argentine ants and native fire ants from two field sites in southern California over a 12 -month period to quantify the extent to which $\delta^{15} \mathrm{~N}$ values drop in response to the spring flush of plant-based resources. Taken together, the approaches developed in this study expand on the current snapshot approach of food-web studies, which often implicitly assume that the trophic position of a focal organism remains stable through time. As a test of this assumption, our study provides quantitative information from controlled laboratory and greenhouse studies concerning how changes in the availability of specific types of resources affect the isotopic signature and trophic position to clarify the results of a comprehensive natural field study of an ecologically important group of insects. 


\section{Materials and methods}

\section{Diet-manipulation experiment I}

In this laboratory-based experiment, we fed Argentine ant colonies either a plant-based diet or an animal-based diet over a 12-week period to quantify the time course over which diet affects $\delta^{15} \mathrm{~N}$. We collected colony material in March 2007 from riparian woodlands in the Tijuana and Otay River Valleys, San Diego Co., California. Ants were collected at ten sites, each separated by at least $1 \mathrm{~km}$. After collection, we divided colony material from every site into a pair of experimental colonies each containing 1,000 workers, five queens, and approximately 50 brood pieces. We housed colonies in circular plastic containers $(28 \mathrm{~cm}$ in diameter) lined with Fluon ${ }^{\text {tm }}$ to prevent ants from escaping. For nesting, we provided ants with 1-L plastic flowerpots filled with autoclaved potting soil, which was moistened with water several times a week. Colonies were reared under standardized conditions (12:12 h light:dark cycle at $22^{\circ} \mathrm{C}$ ) for the duration of the experiment.

For each pair of experimental colonies, we randomly assigned one colony to a plant-based diet and one colony to an animal-based diet. The plant-based diet consisted of Earth's Best ${ }^{\mathrm{tm}}$ Organic First Peas (ingredients: organic peas, water), which had a mean $\delta^{15} \mathrm{~N}$ of $3.8 \%$ and a $\mathrm{C} / \mathrm{N}$ ratio of 9.0. The animal-based diet consisted of Pet Promise $^{\mathrm{tm}}$ Wild Salmon Formula cat food (ingredients: salmon, chicken, fish broth, chicken liver, brown rice, potato protein, and carrots); this food source had a mean $\delta^{15} \mathrm{~N}$ of $5.4 \%$ and a $\mathrm{C} / \mathrm{N}$ ratio of 5.4 . We fed each colony $0.5 \mathrm{~g}$ of treatment diet five times a week. Because $L$. humile experiences high worker mortality when deprived of carbohydrates (Grover et al. 2007), we fed all colonies a $1.5 \%$ weight-on-weight sucrose solution ad libitum. We sampled workers and queens from each replicate at the start of the experiment (i.e., prior to ants consuming treatment diets) and then sampled workers every week for 7 weeks beginning at week 6 . We sampled queens at weeks 6 and 12.

To calculate $\delta^{15} \mathrm{~N}$, we used methods similar to those described in Tillberg et al. (2006, 2007). Individual samples weighed approximately $1,500 \mu \mathrm{g}(10-15$ workers or 1-2 queens) from the same experimental colony; for all samples, only heads, thoraces and legs were used. We collected ants live into empty vials, immediately froze them, and then dried samples at $45-60^{\circ} \mathrm{C}$. After drying, all samples were held in a sealed container with desiccant until processing. We weighed all samples into tin capsules and used a Mettler and Toledo microbalance to estimate mass. Analysis of nitrogen isotopic ratios was performed at the University of California, Davis, Stable Isotope Facility using a Europa Hydra 20/20 continuous-flow IRMS.
For each of the ten pairs of experimental colonies and for each time period in which we sampled ants, we subtracted the $\delta^{15} \mathrm{~N}$ value of workers fed a plant-based diet from that of workers fed an animal-based diet. To test for an increase in these differences over time (i.e., from week 6 to week 12), we used repeated-measures MANOVA and a single degree-of-freedom linear contrast, as recommended by Gurevitch and Chester (1986). The linear contrast tests the hypothesis that the mean difference in $\delta^{15} \mathrm{~N}$ between workers fed the two diets at week 6 differs from this mean difference at week 12. For the $\delta^{15} \mathrm{~N}$ values of queens, we used a paired $t$ test to compare mean differences in $\delta^{15} \mathrm{~N}$ between week 6 and week 12 .

\section{Diet-manipulation experiment II}

To further test how plant-based resources affect the $\delta^{15} \mathrm{~N}$ of Argentine ant workers and to add an element of realism (i.e., compared to use of artificial diets), we conducted a second experiment in which we reared laboratory colonies either with or without honeydew-producing aphids (which provide a common and natural source of plant-based resources). For this manipulation, we used black bean aphids (Aphis fabae solanella), which produce honeydew and are ant-tended, feeding on Solanum nigrum as described in Grover et al. (2008). We conducted this experiment in September and October 2007 in a greenhouse at the University of California San Diego Biology Field Station. Argentine ants used in this experiment came from eight different locations in San Diego Co.; each location was separated by at least $1 \mathrm{~km}$. From material collected at every site, we made a pair of experimental colonies as described in the previous section. In each pair, we randomly assigned colonies to one of two experimental groups: aphids present (animal + plant-based diet, $n=8$ ) and aphids absent (animal-based diet, $n=8$ ).

Before introducing ants to containers with $S$. nigrum, we randomly assigned plants to the two experimental groups under the constraint that half were placed in each group. We inoculated half of the plants with A. $f$. solanella collected from $S$. nigrum growing immediately outside the greenhouse. Each replicate consisted of one potted S. nigrum (in 0.5 -L pots $)$ inside a larger plastic container $(27 \times 66 \times$ $40 \mathrm{~cm}$ ). We spatially interspersed containers in the greenhouse and then added experimental colonies of ants. To prevent ants from escaping, we lined containers with Fluon $^{\mathrm{tm}}$ and balanced them on pedestals in bowls of water. Ants nested in potted S. nigrum. We watered plants three times each week and removed any aphids that colonized plants in the aphids-absent treatment. We also re-inoculated plants in the aphids-present treatment as needed to maintain aphid numbers around 100 per plant for the duration of the experiment. In both aphid and non-aphid treatments, we 
provided colonies with two large (c. $0.50 \mathrm{~g}$ wet weight) frozen crickets (Acheta domesticus) each week but no other food. After 8 weeks, we terminated the experiment and immediately froze all ants. We determined $\delta^{15} \mathrm{~N}$ as described above in "Diet-manipulation experiment I". We used paired $t$ tests to compare the $\delta^{15} \mathrm{~N}$ value of workers with access to plant-based resources (aphids present) to those on a animal-based diet (aphids absent), and to the number of living workers across the two treatments.

\section{Temporal variation in $\delta^{15} \mathrm{~N}$}

To quantify how the $\delta^{15} \mathrm{~N}$ values of free-living ants vary seasonally, we sampled ants monthly in 2006 at two San Diego Co. field sites: the University of California Elliott Chaparral Reserve $\left(32^{\circ} 53.6^{\prime} \mathrm{N}, 117^{\circ} 5.8^{\prime} \mathrm{W}\right)$ and the Tijuana River National Estuarine Research Reserve $\left(32^{\circ} 34.4^{\prime} \mathrm{N}\right.$, $\left.117^{\circ} 7.5^{\prime} \mathrm{W}\right)$. At both sites, invaded areas of chaparral and coastal sage scrub are adjacent to uninvaded areas (Menke et al. 2007; Menke and Holway 2006; Suarez et al. 1998). For comparison with $L$. humile, we sampled colonies of the native fire ant, $S$. xyloni, in adjacent uninvaded areas at each site. In coastal southern California, S. xyloni and $L$. humile are among the most common and widespread ant species but exhibit nearly exclusive distributions, only co-occurring at invasion fronts because $L$. humile displaces S. xyloni (Glenn and Holway 2008; Holway 2005; Menke et al. 2007; Suarez et al. 1998). As a result of the Argentine ant's strong association with moist conditions (Menke and Holway 2006) in coastal southern California, S. xyloni now occurs primarily in seasonally dry scrub, which Argentine ants cannot invade (Menke et al. 2007). Like other fire ants, S. xyloni can act as a behavioral dominant (Ness 2006; Ness et al. 2006) and appears omnivorous (like S. invicta and S. geminata; Tennant and Porter 1991).

At each field site, we collected ants from each of the two focal species mid-month from five fixed sampling locations separated by at least $250 \mathrm{~m}$. For S. xyloni, sampling locations corresponded to individual colonies, whereas for L. humile, all sampling locations fell within the area occupied by the supercolony that extends throughout coastal San Diego Co. (Thomas et al. 2006). For L. humile, we obtained workers every month, and queens and brood when they were present near the soil surface. For S. xyloni, we primarily sampled workers from nest entrances to avoid damaging colonies. We determined $\delta^{15} \mathrm{~N}$ as described above in "Diet-manipulation experiment I". To test for changes in $\delta^{15} \mathrm{~N}$ over time, we used separate repeated-measures MANOVAs for L. humile and S. xyloni. For comparisons of $\delta^{15} \mathrm{~N}$ values between castes, we used paired $t$ tests in which the mean values for individual colonies were used as data points. Two-sample $t$ tests were used to compare mean $\delta^{15} \mathrm{~N}$ values of $L$. humile and $S$. xyloni workers at each site.
Spatial variation in trophic position

To assess how the relative trophic position of $L$. humile and $S$. xyloni changes from site to site, we sampled ants, other arthropods, and plants at four different San Diego Co. sites: the University of California Elliott Chaparral Reserve, the Tijuana River National Estuarine Research Reserve, the Otay-Sweetwater Unit of the San Diego National Wildlife Refuge $\left(32^{\circ} 43.7^{\prime} \mathrm{N}, 116^{\circ} 56.5^{\prime} \mathrm{W}\right)$, and the Torrey Pines State Reserve Extension $\left(32^{\circ} 56.4^{\prime} \mathrm{N}, 117^{\circ} 14.9^{\prime} \mathrm{W}\right)$. We collected biological material between May and July at all sites, but sampled Elliott and Tijuana in 2006, and Sweetwater and Torrey Pines in 2004 and 2005. Like Elliott and Tijuana, Sweetwater and Torrey Pines have areas of chaparral and coastal sage scrub that are invaded by Argentine ants and areas nearby that are not invaded (Glenn and Holway 2008; Tillberg et al. 2007). At each site, we sampled ants from at least five colonies (S. xyloni) or nests ( $L$. humile) to incorporate inter-colony variation in resource assimilation (Tillberg et al. 2006); within-site sampling locations were separated from one another by at least $100 \mathrm{~m}$ and are the experimental units in the analysis. At each site, we also collected known arthropod predators [e.g., scorpions, spiders (Lycosidae, Salticidae), and beetles (Carabidae, Coccinellidae)] and herbivores (e.g., phytophagous Hemiptera, Lepidoptera larvae). Prior to processing, ant and non-ant arthropod samples were homogenized and weighed to $\sim 1,500 \mu \mathrm{g}$ per sample. To estimate basal nitrogen values for the producer trophic level at each site, we collected samples of four to five of the numerically dominant, perennial plant species. We placed plant samples in sealed paper envelopes for drying. Each plant sample was immersed in liquid $\mathrm{N}$ and ground into a fine powder using a mortar and pestle and weighed to $\sim 3,000 \mu \mathrm{g}$. We then obtained $\delta^{15} \mathrm{~N}$ values for ants, non-ants and plants as in "Diet-manipulation experiment I". To estimate relative trophic position from $\delta^{15} \mathrm{~N}$ values, we modified an equation from Post (2002) by establishing a site-specific trophic step (DN); herbivores and predators had similar nitrogen contents, so a correction to account for differences in C:N commonly associated with increasing trophic levels was not necessary (see Mooney and Tillberg 2005). Trophic position was then estimated for each ant species at each sampling location as in Tillberg et al. (2007). We used a two-way ANOVA to compare these values among the four sites and between L. humile and S. xyloni.

\section{Results}

Diet-manipulation experiment I

Repeated measures MANOVA (Wilk's $\lambda=0.052, F_{2,8}=$ 12.16, $p=0.015)$ and the linear contrast $\left(F_{1,9}=19.70\right.$, 
$p=0.002$ ) revealed that the $\delta^{15} \mathrm{~N}$ values of workers fed an animal-based diet increased relative to those of workers fed a plant-based diet between week 6 and week 12 of this experiment (Fig. 1a). The mean $\left( \pm\right.$ SE) $\delta^{15} \mathrm{~N}$ values for workers prior to the diet manipulation experiment was $9.57 \pm 0.42 \%$. After 12 weeks, the mean $\delta^{15} \mathrm{~N}$ for workers fed an animal-based diet was $10.16 \pm 0.42 \%$ equal to a $5.51 \pm 0.01 \%$ increase compared to workers fed a plantbased diet $(9.61 \pm 0.33 \%$ ) (Fig. 1b). During the 6 weeks in which workers were sampled from experimental colonies, the largest single week change in $\delta^{15} \mathrm{~N}$ between workers fed animal and plant-based diets was an increase of $0.50 \pm 0.16 \%$ that occurred between weeks 9 and 10 (Fig. 1a). This increase represents $31 \%$ of the difference between the $\delta^{15} \mathrm{~N}$ values of the diets themselves (animalbased - plant-based diet $=1.62 \%$ ) In contrast to workers, queens from colonies fed experimental diets did not significantly increase their $\delta^{15} \mathrm{~N}$ values between week 6 and week 12, although mean $\delta^{15} \mathrm{~N}$ values did shift in the same direction as those of the workers (Fig. 1a: paired $t$ test: $t_{6}=2.26, p=0.065$ ).

\section{Diet-manipulation experiment II}

After 8 weeks, colonies without access to honeydewproducing aphids (animal-based diet) had lower numbers of workers (279 \pm 86$)$ compared to colonies with access to aphids (plant-based diet) $(677 \pm 85)$ (paired $t$ test: $\left.t_{7}=4.27, p=0.0037\right)$. Moreover, workers from colonies without aphids $\left(9.11 \pm 0.27 \%\right.$ ) had $\delta^{15} \mathrm{~N}$ values that were $6.31 \pm 0.02 \%$ higher compared to those of workers from colonies fed crickets and provided with access to honeydew-producing aphids $(8.59 \pm 0.30 \%$ ) (paired $t$ test: $\left.t_{7}=2.60, p=0.035\right)$.

\section{Temporal variation in $\mathrm{d} 15 \mathrm{~N}$}

Nitrogen isotopic ratios of Argentine ant workers and brood exhibited considerable variation among sampling locations within both study sites (Fig. 2a, b). In part because of this variation, repeated-measures MANOVAs did not detect significant effects of time despite evident monthly fluctuations in mean $\delta^{15} \mathrm{~N}$ (Fig. 2a-b). Averaged over time, $\delta^{15} \mathrm{~N}$ values for Argentine ant workers were higher than those of brood at both study sites. Time-averaged mean $( \pm \mathrm{SE}) \delta^{15} \mathrm{~N}$ values for Elliott were $6.26 \pm 0.22 \%$ (workers) versus $5.62 \pm 0.21 \%$ o (brood) (paired $t_{4}=6.14, p=0.0036$ ). Time-averaged mean $( \pm \mathrm{SE}) \delta^{15} \mathrm{~N}$ values for Tijuana were $12.16 \pm 0.30 \%$ o (workers) versus $10.97 \pm 0.31 \%$ (brood) (paired $t_{4}=4.13, p=0.014$ ). More thorough sampling from the Tijuana site also permitted additional caste comparisons. Compared to the $\delta^{15} \mathrm{~N}$ values of workers, those of male reproductives averaged lower (time-averaged
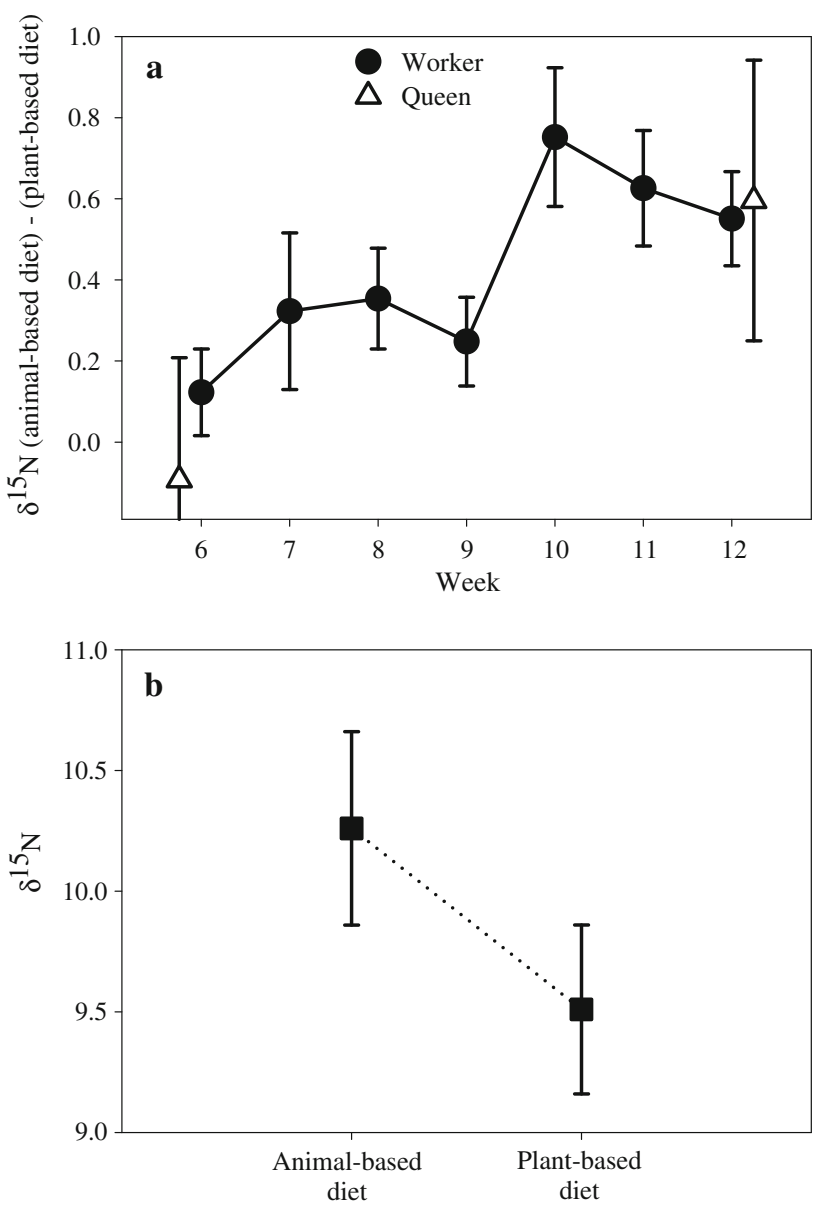

Fig. 1 a Results of diet-manipulation experiment I. Mean $( \pm S E)$ difference in $\delta^{15} \mathrm{~N}$ for workers (filled circles) and queens (open triangles) from colonies fed animal-based versus plant-based diets. b Mean $( \pm \mathrm{SE}) \delta^{15} \mathrm{~N}$ of workers from 10 paired colonies with access to animal-based diet or plant-based diet after 12 weeks. For nine of ten colony pairs, the $\delta^{15} \mathrm{~N}$ value for the colony fed an animal-based diet was higher than that of the colony fed a plantbased diet

mean \pm SE for males $=11.15 \pm 0.46 \%$; paired $t_{4}=2.84$, $p=0.047$ ), whereas those of queens appeared higher (timeaveraged mean $\pm \mathrm{SE}$ for queens $=13.51 \pm 0.58 \%$; paired $t_{4}=2.10, p=0.10$ ).

Like the $\delta^{15} \mathrm{~N}$ values of Argentine ant workers, those of fire ant workers exhibited considerable spatio-temporal variation (Fig. 2c, d), but both species exhibited comparable $\delta^{15} \mathrm{~N}$ values when these measures were averaged across monthly sampling periods. Time-averaged mean \pm SE $\delta^{15} \mathrm{~N}$ values for Elliott were $6.26 \pm 0.22 \%$ o (Linepithema humile workers) versus $6.23 \pm 0.12 \%$ o (Solenopsis xyloni workers) (two-sample $t$ test $_{6.4}=0.09: p>0.05$ ). Time-averaged mean $\pm \mathrm{SE} \delta^{15} \mathrm{~N}$ values for Tijuana were $12.16 \pm 0.30 \%$ (Linepithema humile workers) versus $11.67 \pm 0.30 \%$ (Solenopsis xyloni workers) (two-sample $t$ test $\left._{10.3}=1.14: p>0.05\right)$. 
Fig. 2 Mean $\left( \pm\right.$ SE) $\delta^{15} \mathrm{~N}$ values for a,b Linepithema humile workers (filled circles) and brood (open circles), and c,d Solenopsis xyloni workers (open squares) from the University of California Elliott Chaparral Reserve and Tijuana River National Estuarine Research Reserve. $X$-axis shows duration of sampling by month; January $(J)$ to December $(D)$, and the time-averaged mean across months
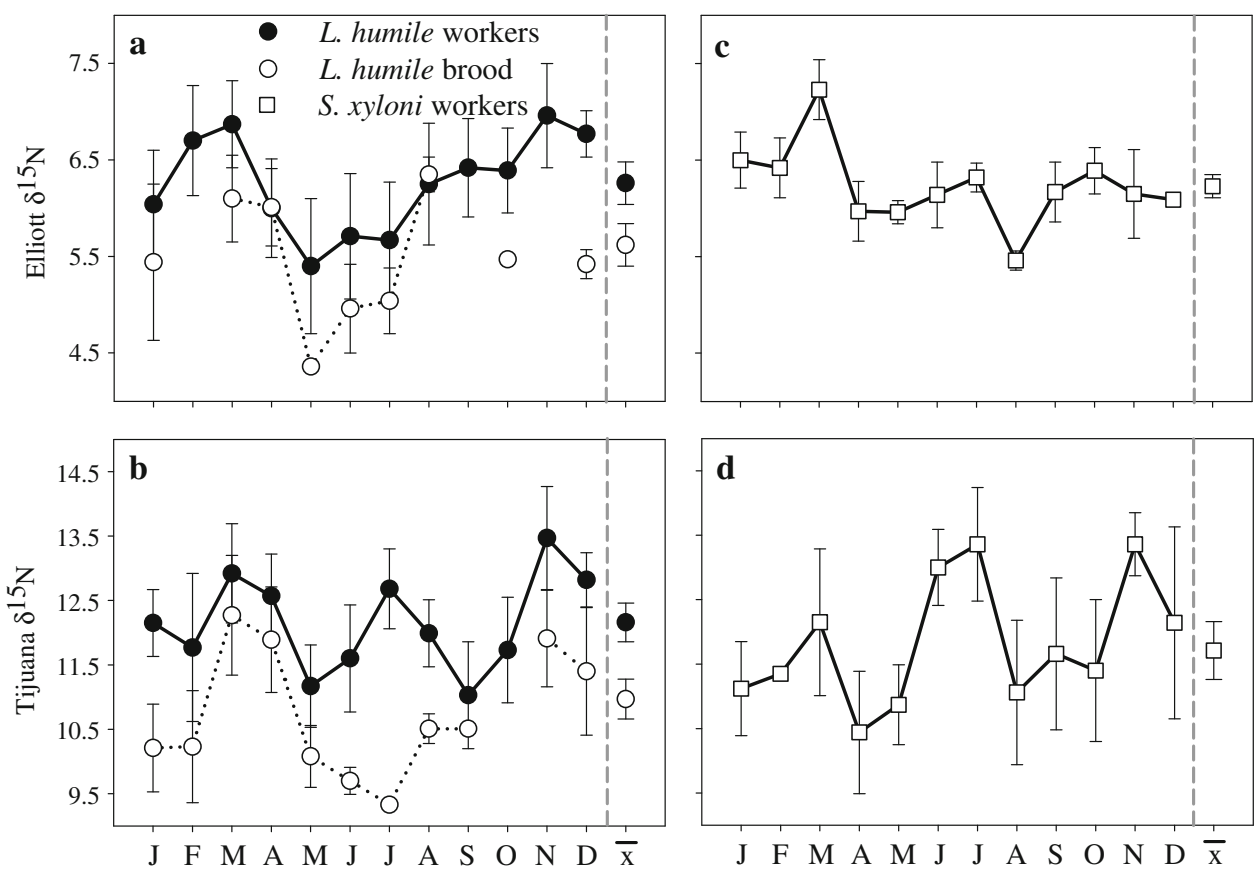

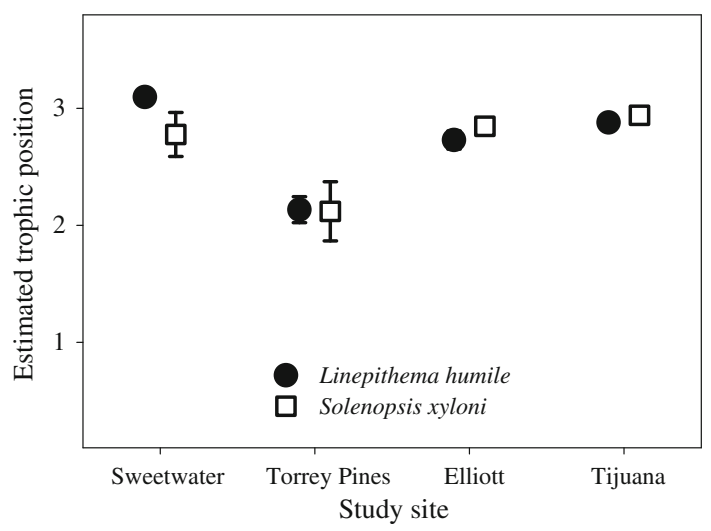

Fig. 3 Mean \pm SE estimates of trophic position (1 primary producer, 2 herbivore, 3 primary predator, 4 secondary predator) for Linepithema humile (filled circles) and Solenopsis xyloni (open squares) from the Otay-Sweetwater Unit of the San Diego National Wildlife Refuge (Sweetwater), Torrey Pines State Reserve Extension (Torrey Pines), University of California Elliott Chaparral Reserve (Elliott), and Tijuana River National Estuarine Research Reserve (Tijuana)

\section{Spatial variation in trophic position}

Factorial comparisons of estimated trophic position for $L$. humile and S. xyloni at four different sites revealed significant effects of location (two-way ANOVA: $F_{3,68}=$ $17.85, p<0.0001)$ but no effect of species $\left(F_{1,68}=0.41\right.$, $p=0.84)$ and no interaction $\left(F_{3,68}=2.00, p=0.12\right)$ (Fig. 3). Of the four sites sampled, L. humile and S. xyloni from Torrey Pines had the lowest estimates of trophic position compared to the ants from the other three sites (Fisher's PLSD: $p<0.0001$ ). Estimates of trophic position for ants from Elliott, Tijuana and Sweetwater did not differ from one another (Fisher's PLSD: $p>0.05$ ).

\section{Discussion}

This study uses laboratory experiments to inform the results of field data and reports novel information concerning temporal and spatial patterns of resource assimilation by invasive ants and the native ants they displace. Quantitative information concerning the diets of invasive ants remains surprisingly scant (but see Tennant and Porter 1991; Tillberg et al. 2007), and the approaches developed in this study promise to enhance an understanding of what these insects consume and thus how they interact with other organisms. Furthermore, our results underscore that the ecological interpretation of isotopic data requires careful consideration.

Our diet-manipulation experiments illustrate how nitrogen isotopic data may be used to examine spatiotemporal patterns of resource assimilation by ant colonies and in particular the degree to which invasive ants monopolize plant-based, carbohydrate-rich resources; a phenomenon that appears linked with invasion success (Davidson 1998; Grover et al. 2007; Helms and Vinson 2002, 2008). As expected based on known patterns of nitrogen fractionation (Cabana and Rasmussen 1994; Feldhaar et al. 2009; Mooney and Tillberg 2005; Owens 1987), workers from colonies fed animal-based diets had higher $\delta^{15} \mathrm{~N}$ values compared to those fed plant-based diets. Interestingly, differences in $\delta^{15} \mathrm{~N}$ values between 
treatments were largest after 10 weeks from the start of the experiment (Fig. 1a). Based on known rates of development under laboratory conditions (Newell and Barber 1913), this time interval approximately coincides with the eclosion of the first cohort of workers that were eggs at the start of the experiment (i.e., workers that spent their entire larval period under the dietary regimes of this study). Modest increases in $\delta^{15} \mathrm{~N}$ values prior to 10 weeks may have resulted from larvae that developed partially on treatment diets as well as cellular turnover in the tissues of workers that eclosed prior to the start of the experiment. The temporal pattern evident in Fig. 1 illustrates how $\delta^{15} \mathrm{~N}$ values of workers could be used to identify seasonal shifts in the assimilation of carbohydrate-rich resources (e.g., flushes of primary production or spikes in the abundance of honeydew-producing Hemiptera). This temporal pattern also highlights potential complications of interpreting $\delta^{15} \mathrm{~N}$ values from field-based worker collections. Because living workers in any ant colony are demographically mixed, $\delta^{15} \mathrm{~N}$ values from field-collected workers represent timeaveraged estimates of a colony's foraging history, without revealing seasonal shifts in diet (Feldhaar et al. 2009).

The second diet-manipulation experiment added an element of realism to our study; under natural conditions, Argentine ants forage extensively on honeydew and scavenged arthropods (Human et al. 1998; Markin 1970; Newell and Barber 1913; Zee and Holway 2006). After 8 weeks, workers from colonies fed only crickets had higher $\delta^{15} \mathrm{~N}$ values, on average, compared to those of workers fed crickets and also provided with access to honeydew-producing aphids. Because conditions in the greenhouse where we conducted the second diet-manipulation experiment averaged considerably warmer than those experienced by ants in the laboratory (where we conducted the first diet-manipulation experiment), development times in the second diet-manipulation study were no doubt shorter than those in the laboratory study. The results of the greenhouse experiment suggest that $\delta^{15} \mathrm{~N}$ values may be used to estimate spatial differences in the assimilation of carbohydrate-rich resources (e.g., adjacent habitats that differ in the availability of such resources, say as a result of differences in primary production).

Although the diet-manipulation experiments clearly indicate how assimilation of plant-based resources reduces the $\delta^{15} \mathrm{~N}$ values of Argentine ant workers after approximately 10 weeks, we failed to detect a drop in $\delta^{15} \mathrm{~N}$ values in field colonies during spring and early summer (from March-June) (Fig. 2a, b) when access to plant-based resources (e.g., nectar and honeydew) would presumably peak in the scrub communities sampled. Although both L. humile and S. xyloni workers from field colonies exhibited a drop in $\delta^{15} \mathrm{~N}$ values of roughly $1 \%$ between March and June, our inability to detect an effect of time in the repeated-measures MANOVA could be attributed to within-site variability and modest sample sizes $(n=5$ sampling locations at each of two sites). It also seems possible that the scrub habitats sampled do not provide large amounts of accessible plant-based carbohydrates for Argentine ants. Chaparral and coastal sage scrub have relatively low NPP compared to other areas invaded by Argentine ants (e.g., riparian areas, irrigated urban areas). Many scrub plant species bloom in late winter and early spring, support few, if any, honeydew-producing Hemiptera, and become largely dormant during the long summer drought (May-October). Large inter-site differences in $\delta^{15} \mathrm{~N}$ values between Tijuana and Elliott presumably result from the marine influence at the coastal Tijuana site.

An additional reason why field sampling failed to reveal a clear seasonal shift in $\delta^{15} \mathrm{~N}$ values may have resulted from the demographic complexity of field colonies. In the field, the composition of individual nests exhibits turnover not only through worker birth and death but also potentially through emigration and immigration of workers from adjacent nests where workers could be feeding on different resources. As with Tillberg et al. (2006) (see also Kay et al. (2006), we found that development stages differed in their $\delta^{15} \mathrm{~N}$ values (Fig. 2a, b). These differences partly result from processing (e.g., workers, males and queens had gasters removed, whereas brood were sampled whole) but probably also from ontogenetic disparities in resource assimilation. Argentine ant larvae, for example, require both proteins and carbohydrates to complete development (Grover et al. 2007). We also observed significant differences in $\delta^{15} \mathrm{~N}$ values between workers and male alates. Taken together, these findings illustrate that the use of isotopic data as a tool to study social insect diets requires careful consideration of developmental stage and caste.

The observed variation in $\delta^{15} \mathrm{~N}$ values over space and time and among castes (Fig. 2) indicates that the ecological interpretation of social insects function within arthropod food webs may well be more complicated than generally acknowledged. In particular, caution seems warranted in using stable isotopic data to make ecological inferences when measurements come from single colonies, time periods, or life stages. Seasonal variation in $\delta^{15} \mathrm{~N}$ values, in particular, requires additional scrutiny. While the seasonal differences in $\delta^{15} \mathrm{~N}$ values from the field were not as great as those from our diet-manipulation experiments, the seasonal variation in $\delta^{15} \mathrm{~N}$ values of workers from free-living colonies span approximately one trophic step. It remains unclear whether this variation results more from seasonal changes in resource availability or from shifts in resource preferences at different points in the colony cycle. Discriminating between these two mechanisms is complicated by the presence of overlapping generations within eusocial insect colonies and because it is unknown how the nitrogen 
isotopic ratio of individual workers changes over the course of development.

An unexpected result to emerge from our study concerns broad similarities between $L$. humile and S. xyloni workers with respect to temporal variation in $\delta^{15} \mathrm{~N}$ values (Fig. 2) and spatial patterns of estimated trophic position (Fig. 3). Although both ant species can achieve ecological dominance, $S$. xyloni differs from the Argentine ant in its tolerance of hot, dry conditions (Schilman et al. 2005), its colony structure (multicolonial versus unicolonial for the Argentine ant), its tendency to cease above-ground foraging in winter (at least in southern California), and probably also in its more hypogeic nature. Despite these trait differences, isotopic data indicate that the resources assimilated by $S$. xyloni roughly correspond to those assimilated by $L$. humile. Interestingly, a comparable pattern exists in northern Argentina at sites where L. humile co-exists with $S$. invicta and S. richteri (LeBrun et al. 2007; Tillberg et al. 2007).

\section{Conclusions}

This study is of general relevance to food web studies because it documents extensive spatio-temporal variation in the trophic ecology of prominent members of terrestrial food webs. These results contribute to a growing literature that conceptualizes food webs as inherently dynamic entities (Layman et al. 2007; Schmidt et al. 2007). Time and place matter when developing a picture of the consumptive interactions within a food web. Accurate assessments of food web dynamics involving focal species must account for differences in trophic position among among sites and over time. The incorporation of spatio-temporal variation into food web theory adds an important element of realism to models of trophic interactions (Schmidt et al. 2007).

\begin{abstract}
Acknowledgments We would like to thank P. Lester and two anonymous reviewers for their comments on the manuscript. This research was supported by grants from the U.S. Department of Agriculture (NRI-CGP 2006-35302-17255 to D.A.H.), the National Science Foundation (DEB 07-16966 to A.V.S. and D.A.H.), and the Research Fellowship grant from NOAA's Office of Ocean and Coastal Resource Management, Estuarine Reserves Division to S.B.M.
\end{abstract}

Open Access This article is distributed under the terms of the Creative Commons Attribution Noncommercial License which permits any noncommercial use, distribution, and reproduction in any medium, provided the original author(s) and source are credited.

\section{References}

Cabana G, Rasmussen JB (1994) Modelling food chain structure and contaminant bioaccumulation using stable nitrogen isotopes. Nature 372:255-257
Davidson DW (1998) Resource discovery versus resource domination in ants: a functional mechanism for breaking the trade-off. Ecol Entomol 23:484-490

Davidson DW, Cook SC, Snelling RR, Chua TH (2003) Explaining the abundance of ants in lowland tropical rainforest canopies. Science 300:969-972

Dawson TE, Mambelli S, Plamboeck AH, Templer PH, Tu KP (2002) Stable isotopes in plant ecology. Annu Rev Ecol Syst 33:507559

Deniro MJ, Epstein S (1981) Influence of diet on the distribution of nitrogen isotopes in animals. Geochim Cosmochim Acta 45:341-351

Diamond J, Case TJ (1986) Overview: introductions, extinctions, exterminations, and invasions. In: Diamond J, Case TJ (eds) Community ecology. Harper and Row, New York, pp 65-79

Ehleringer JR, Rundel PW, Nagy KA (1986) Stable isotopes in physiological ecology and food web research. Trends Ecol Evol 1:42-45

Elton CS (1958) The ecology of invasions by animals and plants. University of Chicago Press, Chicago

Feldhaar H, Gebauer G, Blüthgen N (2009) Stable isotopes: past and future in exposing secrets of ant nutrition (Hymenoptera: Formicidae). Myrmecol News 13:3-13

Fritts TH, Rodda GH (1998) The role of introduced species in the degradation of island ecosystems: a case history of Guam. Annu Rev Ecol Syst 29:113-140

Gannes LZ, O'Brien DM, Del Rio CM (1997) Stable isotopes in animal ecology: assumptions, caveats, and a call for more laboratory experiments. Ecology 78:1271-1276

Glenn S, Holway D (2008) Consumption of introduced prey by native predators: Argentine ants and pit-building ant lions. Biol Invasions 10:273-280

Gorokhova E, Hansson S, Höglander H, Andersen CM (2005) Stable isotopes show food web changes after invasion by the predatory cladoceran Cercopagis pengoi in a Baltic Sea bay. Oecologia 143:251-259

Grover CD, Kay AD, Monson JA, Marsh TC, Holway DA (2007) Linking nutrition and behavioural dominance: carbohydrate scarcity limits aggression and activity in Argentine ants. Proc R Soc Lond B 274:2951-2957

Grover CD, Dayton KC, Menke SB, Holway DA (2008) Effects of aphids on foliar foraging by Argentine ants and the resulting effects on other arthropods. Ecol Entomol 33:101-106

Gurevitch J, Chester ST Jr (1986) Analysis of repeated measures experiments. Ecology 67:251-255

Helms KR, Vinson B (2002) Widespread association of the invasive ant Solenopsis invicta with an invasive mealybug. Ecology 83:2425-2438

Helms KR, Vinson S (2008) Plant resources and colony growth in an invasive ant: the importance of honeydew-producing hemiptera in carbohydrate transfer across trophic levels. Environ Entomol 37:487-493

Holway DA (2005) Edge effects of an invasive species across a natural ecological boundary. Biol Conserv 121:561-567

Holway DA, Lach L, Suarez AV, Tsutsui ND, Case TJ (2002) The causes and consequences of ant invasions. Annu Rev Ecol Syst 33:181-233

Human KG, Weiss S, Weiss A, Sandler B, Gordon DM (1998) Effects of abiotic factors on the distribution and activity of the invasive Argentine ant (Hymenoptera : Formicidae). Environ Entomol 27:822-833

Kay AD, Rostampour S, Sterner RW (2006) Ant stoichiometry: elemental homeostasis in stage-structured colonies. Funct Ecol 20:1037-1044

Lach L (2003) Invasive ants: unwanted partners in ant-plant interactions? Ann Mo Bot Gard 90:91-108 
Langellotto G, Rosenheim J, Williams M (2006) Assessing trophic interactions in a guild of primary parasitoids and facultative hyperparasitoids: stable isotope analysis. Oecologia 150:291299

Layman CA, Arrington DA, Montaña CG, Post DM (2007) Can stable isotope ratios provide for community-wide measures of trophic structure? Ecology 88:42-48

LeBrun EG, Tillberg CV, Suarez AV, Folgarait PJ, Smith CR, Holway DA (2007) A study of competition between red imported fire ants and Argentine ants in their native range. Ecology 88:63-75

Mack RN, Simberloff D, Lonsdale WM, Evans H, Clout M, Bazzaz FA (2000) Biotic invasions: causes, epidemiology, global consequences, and control. Ecol Appl 10:689-710

Markin GP (1970) Seasonal life cycle of Argentine ant, Iridomyrmex humilis (Hymenoptera, Formicidae), in Southern California. Ann Entomol Soc Am 63:1238-1242

McCutchan JH, Lewis WM, Kendall C, McGrath CC (2003) Variation in trophic shift for stable isotope ratios of carbon, nitrogen, and sulfur. Oikos 102:378-390

Menke SB, Holway DA (2006) Abiotic factors control invasion by Argentine ants at the community scale. J Anim Ecol 75:368-376

Menke SB, Fisher RN, Jetz W, Holway DA (2007) Biotic and abiotic controls of Argentine ant invasion success at local and landscape scales. Ecology 88:3164-3173

Minagawa M, Wada E (1984) Stepwise enrichment of $15 \mathrm{~N}$ along food chains: further evidence and the relation between [delta] $15 \mathrm{~N}$ and animal age. Geochim Cosmochim Acta 48:1135-1140

Mooney KA, Tillberg CV (2005) Temporal and spatial variation to ant omnivory in pine forests. Ecology 86:1225-1235

Ness JH (2006) A mutualism's indirect costs: the most aggressive plant bodyguards also deter pollinators. Oikos 113:506-514

Ness JH, Morris WF, Bronstein JL (2006) Integrating quality and quantity of mutualistic service to contrast ant species protecting Ferocactus wislizeni. Ecology 87:912-921

Newell W, Barber TC (1913) The Argentine ant. USDA Bureau Entomol Bull 122:1-98

O'Dowd DJ, Green PT, Lake PS (2003) Invasional 'meltdown' on an oceanic island. Ecol Lett 6:812-817

Oelbermann K, Scheu S (2002) Stable isotope enrichment (d15N and $\mathrm{d} 13 \mathrm{C}$ ) in a generalist predator (Pardosa lugubris, Araneae: Lycosidae): effects of prey quality. Oecologia 130:337-344

Ostrom PH, Colunga-Garcia M, Gage SH (1997) Establishing pathways of energy flow for insect predators using stable isotope ratios: field and laboratory evidence. Oecologia 109:108-113

Owens NJP (1987) Natural variations in $15 \mathrm{~N}$ in the marine environment. In: Blaxter JHS, Southward AJ (eds) Advances in marine biology, vol 24. Academic, pp 389-451

Petren K, Case TJ (1998) Habitat structure determines competition intensity and invasion success in gecko lizards. Proc Natl Acad Sci USA 95:11739-11744

Pimm SL, Lawton JH, Cohen JE (1991) Food web patterns and their consequences. Nature 350:669-674

Polis GA, Power ME, Huxel GR (2004) Food webs at the landscape level. University of Chicago Press, Chicago

Post DM (2002) Using stable isotopes to estimate trophic position: models, methods, and assumptions. Ecology 83:703-718

Rudnick D, Resh V (2005) Stable isotopes, mesocosms and gut content analysis demonstrate trophic differences in two invasive decapod crustacea. Freshw Biol 50:1323-1336

Sagers C, Goggin F (2007) Isotopic enrichment in a phloem-feeding insect: influences of nutrient and water availability. Oecologia $151: 464-472$
Sanders NJ, Gotelli NJ, Heller NE, Gordon DM (2003) Community disassembly by an invasive species. Proc Natl Acad Sci USA 100:2474-2477

Schilman PE, Lighton JRB, Holway DA (2005) Respiratory and cuticular water loss in insects with continuous gas exchange: comparison across five ant species. J Insect Physiol 51:12951305

Schmidt SN, Olden JD, Solomon CT, Zanden MJV (2007) Quantitative approaches to the analysis of stable isotope food web data. Ecology 88:2793-2802

Snyder WE, Evans EW (2006) Ecological effects of invasive arthropod generalist predators. Annu Rev Ecol Evol Syst 37:95-122

Spence K, Rosenheim J (2005) Isotopic enrichment in herbivorous insects: a comparative field-based study of variation. Oecologia 146:89-97

Suarez AV, Bolger DT, Case TJ (1998) Effects of fragmentation and invasion on native ant communities in coastal southern California. Ecology 79:2041-2056

Suarez AV, Holway DA, Case TJ (2001) Patterns of spread in biological invasions dominated by long-distance jump dispersal: insights from Argentine ants. Proc Natl Acad Sci USA 98:10951100

Tennant LE, Porter SD (1991) Comparison of diets of two fire ant species (Hymenoptera: Formicidae): solid and liquid components. J Entomol Sci 26:450-465

Thomas ML, Payne-Makrisa CM, Suarez AV, Tsutsui ND, Holway DA (2006) When supercolonies collide: territorial aggression in an invasive and unicolonial social insect. Mol Ecol 15:43034315

Tillberg CV (2004) Friend or foe? A behavioral and stable isotopic investigation of an ant-plant symbiosis. Oecologia 140:506-515

Tillberg CV, Breed MD (2004) Placing an omnivore in a complex food web: dietary contributions to adult biomass of an ant. Biotropica 36:266-271

Tillberg C, McCarthy D, Dolezal A, Suarez A (2006) Measuring the trophic ecology of ants using stable isotopes. Insectes Soc 53:65-69

Tillberg CV, Holway DA, LeBrun EG, Suarez AV (2007) Trophic ecology of invasive Argentine ants in their native and introduced ranges. Proc Natl Acad Sci USA 104:20856-20861

Treseder KK, Davidson DW, Ehleringer JR (1995) Absorption of antprovided carbon dioxide and nitrogen by a tropical epiphyte. Nature 375:137-139

Vander Zanden MJ, Casselman JM, Rasmussen JB (1999) Stable isotope evidence for the food web consequences of species invasions in lakes. Nature 401:464-467

Vanderklift M, Ponsard S (2003) Sources of variation in consumerdiet $\delta 15 \mathrm{~N}$ enrichment: a meta-analysis. Oecologia 136:169-182

Vitousek PM, D'Antonio CM, Loope LL, Westbrooks R (1996) Biological Invasions as global environmental change. Am Sci 84:468-478

Wilson EE, Mullen LM, Holway DA (2009) Life history plasticity magnifies the ecological effects of a social wasp invasion. Proc Natl Acad Sci USA 106:12809-12813

Zee J, Holway D (2006) Nest raiding by the invasive Argentine ant on colonies of the harvester ant, Pogonomyrmex subnitidus. Insectes Soc 53:161-167 